\title{
A dual adaptive tunable vibration absorber using MREs for vehicle powertrain vibration control
}

\author{
$\mathrm{N}$ Hoang*a, ${ }^{*}, \mathrm{~N}$ Zhang ${ }^{\mathrm{a}}$ and $\mathrm{H} \mathrm{Du} \mathrm{u}^{\mathrm{a}, \mathrm{c}}$ \\ ${ }^{a}$ School of Electrical, Mechanical and Mechatronics Systems, Faculty of Engineering \\ University of Technology, Sydney, PO Box 123, Broadway, NSW 2007, Australia \\ ${ }^{\mathrm{b}}$ Institute of Mechanics, 264 Doican, Hanoi, Vietnam \\ ${ }^{\mathrm{c}} \mathrm{School}$ of Electrical, Computer and Telecommunications Engineering, University of Wollongong, \\ Northfields Avenue, NSW 2522, Australia
}

\begin{abstract}
This paper presents a dual Adaptive Tuned Vibration Absorber (ATVA) using a magnetorheological elastomer (MRE) for powertrain torsional vibration control. The MRE used in this device is a soft MRE with a significant MR effect. By using the MRE, the ATVA can work in a wide frequency range. In this paper, the dual ATVA is proposed rather than a single ATVA because a single ATVA, at a fixed location, cannot deal with resonances happening to several powertrain vibration modes. Also, the dual ATVA concept design is presented to validate its effectiveness. In addition the soft MRE shear modulus is approximated by a polynomial of magnetic flux intensity B and the approximation was experimentally validated. The simulation results showed that with the ATVA; powertrain vibration response is significantly suppressed. Furthermore, the effect of the dual ATVA parameters such as inertia moment, stiffness and damping coefficients and ATVA locations were examined. The dual ATVA will be useful device for powertrain vibration suppression.
\end{abstract}

Keywords: dual dynamic absorber, vibration control, powertrain vibration, magnetorheological elastomer.

\section{INTRODUCTION}

Magnetorheological elastomer (MRE) is a smart material, which has elastic moduli can be controlled by an external magnetic field. In other words, the stiffness of MREs can be controlled magnetically ${ }^{1,2}$. Thus, MREs have been used for developing ATVAs (Adaptive Tuned Vibration Absorbers) ${ }^{3.4-5}$. Ginder et al. ${ }^{3}$ were the first authors who developed an ATVA using a MRE. Deng et $\mathrm{al}^{4}$ developed an ATVA for a beam with two supported ends. Lerner and Cunefare developed a state-switched absorber using a MRE. However, so far the MRE has been used for developing ATVAs for single degree-of-freedom (SDOF) applications only. Actually, most real world structures and mechanisms have multi degrees of freedom (MDOF). This drawback limits the application of MREs to engineering problems.

A vehicle powertrain is a term referring to a crucial component of automobiles for delivering power from engine to vehicle tires. It consists of an engine, a clutch and a transmission gear box and drive line components such as the differentials, wheel tires. ${ }^{6}$. Obviously, powertrain is a MDOF system and it is one of major sources of vibration of vehicles because of excitation of the engine periodic fluctuation torque ${ }^{7}$. Citron and O'higgins ${ }^{8}$ reported that the fluctuation torque can be expressed as sum of harmonics whose frequencies are multiples of fundamental frequency. When frequencies of these harmonics are close to one or few frequencies of the powertrain, its vibration can be increased significantly. The high level vibration reduces the vehicle ride comfort or may wear or damage powertrain components.

Dual absorbers have been used widely in many applications, ${ }^{9-13}$. Yamashita et al ${ }^{9}$ designed dual dynamic absorbers for reduction of vibration of piping system. In line with these authors, Yan and $\operatorname{Lin}^{10}$ developed a dual dynamic absorber for suppressing the computer hard disk driver. Burdisso and Heilmann ${ }^{11}$ used a dual dynamic absorber for vibration reduction of a structure. Iwanami and Seto ${ }^{12}$ optimized design parameters of a dual dynamic absorber for SDOF system. Al-Bedoor and Moustafa ${ }^{13}$ used a dual dynamic absorber for reduction of start-up vibration of synchronous motor-driven compressors, which is modeled as MDOF system. Even though these studies showed that there are several advantages of using dual ATVAs to single ones, the role of vibration mode shapes of the primary MDOF system has not been fully addressed. Especially, the application of dual ATVA for two resonances at the same time has not been investigated.

*Nga.Hoang@eng.uts.edu.au; phone +612 9514 3148; fax +61 29514 2655; 
Zhang et al ${ }^{14}$ used a dual ATVA using an enhanced MRE for powertrain suppression under a multi-harmonic excitation. Although the study report that the frequency rang of MRE material can be increased significantly, there are two main shortcomings of this study. Firstly, the MRE used in this case is still in theory model and its mechanical properties such as shear modulus have not been experimentally validated yet. Secondly, the ATVA damping, which effects significantly to the ATVA effectiveness has been ignored. These shortcomings will be deal with in this work.

The aim of this paper is to present a dual MRE-based ATVA rather than a single ATVA because of two main reasons. The first one is that the effectiveness of a single ATVA for the primary MDOF powertrain system depends on not only the ATVA parameters such as inertia moment, stiffiness and damping coefficients but also on the powertrain vibration mode shapes. In other words, if a single ATVA is installed at a fixed position in the powertrain, it may work effectively only with one or few powertrain frequencies. That means this single ATVA will not be able to deal with resonances happening to the other powertrain frequencies although these frequencies are in its working frequency range. The second reason is that a single ATVA cannot deal with more than one resonance at the same time while vehicle's engine fluctuation torque is a multi-frequency excitation because of the internal combustion engine feature. According to the engine speed, the dual ATVA frequency can be tuned to shift powertrain frequencies away from resonances, which occur to several powertrain vibration modes. This device will be an innovative device for powertrain vibration reduction.

\section{A POWERTRAIN SYSTEM AND ITS VIBRATION CHARACTERISTICS}

A powertrain torsional vibration model, which consists of inertias, stiffnesses and dampings, is shown in figure 1 . In the model, the vehicle engine is modelled by the first inertia and the clutch, the gear box of transmission and the drive line components are presented by the second, third and the fourth inertia, respectively.

It is noted that the powertrain has a number of gear ratios. These gear ratios are used to set the optimal engine speed according to the vehicle speed. In this study, four gear ratios are investigated so that there are four gear shifts as well. At each gear shift, a few associated gears are engaged to provide a fixed gear ratio, which is called as the first gear, second gear, third gear or the fourth gear of gear box, respectively. The stiffness coefficient of these four gears is modelled by varying the stiffness coefficient $\mathrm{k}_{2}$.

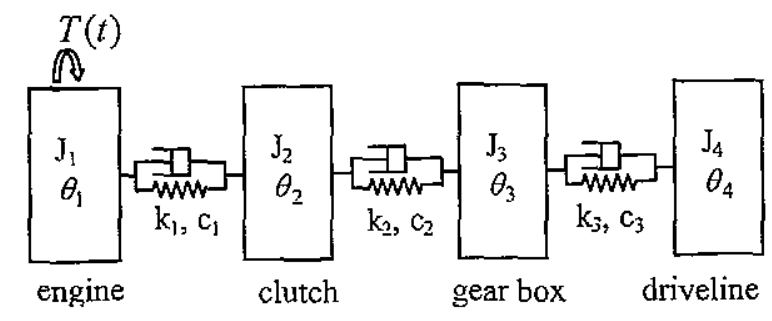

Figure 1. A vehicle powertrain model.

By using Lagrange's equation, the equation of motion of the system can be expressed as below:

$$
\mathbf{J} \ddot{\boldsymbol{\theta}}+\mathbf{C} \dot{\boldsymbol{\theta}}+\mathbf{K} \boldsymbol{\theta}=\mathbf{T}
$$

Where $\boldsymbol{\theta}=\left[\begin{array}{llll}\theta_{1} & \theta_{2} & \theta_{3} & \theta_{4}\end{array}\right]^{T}, \mathbf{T}=\left[\begin{array}{llll}T(t) & 0 & 0 & 0\end{array}\right]^{T}$ are vectors of generalized coordinates and the external torque. $T(t)$ is the engine toque. The inertial matrix is diagonal one, $\mathbf{J}=\operatorname{diagonal}\left(\mathrm{J}_{1}, \mathrm{~J}_{2}, \mathrm{~J}_{3}, \mathrm{~J}_{4}\right)$ and stiffness and damping matrices, $\mathbf{K}$ and $C$, have following forms:

$$
\mathbf{K}=\left[\begin{array}{cclc}
k_{1} & -k_{1} & 0 & 0 \\
-k_{1} & k_{1}+k_{2} & -k_{2} & 0 \\
0 & -k_{2} & k_{2}+k_{3} & -k_{3} \\
0 & 0 & -k_{3} & k_{3}
\end{array}\right] ; \mathbf{C}=\left[\begin{array}{cccc}
c_{1} & -c_{1} & 0 & 0 \\
-c_{1} & c_{1}+c_{2} & -c_{2} & 0 \\
0 & -c_{2} & c_{2}+c_{3} & -c_{3} \\
0 & 0 & -c_{3} & c_{3}
\end{array}\right]
$$

By solving equation (1), it is straightforward to obtain powertrain vibration features such as frequencies, mode shap $\equiv$ and responses. Let $\mathrm{J}_{1}=0.8, \mathrm{~J}_{2}=0.25, \mathrm{~J}_{3}=0.5, \mathrm{~J}_{4}=8 \mathrm{kgm}^{2} ; \mathrm{c}_{1}=5.0, \mathrm{c}_{2}=10.0, \mathrm{c}_{3}=15.0 \mathrm{Nms} / \mathrm{rad} ; \mathrm{k}_{1}=20000, \mathrm{k}_{3}=10000 \mathrm{Nm} \mathrm{rad}$. Iaddition, $\mathrm{k}_{2}=13000,15000,16000$ and $18000 \mathrm{Nm} / \mathrm{rad}$ are set for the first, second, third and fourth gear, respective $\because$ With these parameters, powertrain natural frequencies and damping ratios $\zeta$ for the second gear of gear box are show $:-$ Table 1 . 
Table 1. Natural frequencies of a simplified powertrain model for four gear ratios of gear box.

\begin{tabular}{ccccccccc} 
& \multicolumn{2}{c}{ first gear } & \multicolumn{2}{c}{ second gear } & \multicolumn{2}{c}{ third gear } & \multicolumn{2}{c}{ fourth gear } \\
index & $\mathrm{f}(\mathrm{Hz})$ & $\zeta(\%)$ & $\mathrm{f}(\mathrm{Hz})$ & $\zeta(\%)$ & $\mathrm{f}(\mathrm{Hz})$ & $\zeta(\%)$ & $\mathrm{f}(\mathrm{Hz})$ & $\zeta(\%)$ \\
\hline $\mathrm{f}_{1}$ & $0^{\mathrm{a}}$ & & $0^{\mathrm{a}}$ & & $0^{\mathrm{a}}$ & & $0^{\mathrm{a}}$ & \\
$\mathrm{f}_{2}$ & $11.0494^{\mathrm{b}}$ & 3.91 & 11.2758 & 3.96 & 11.3708 & 3.99 & 11.5329 & 4.06 \\
$\mathrm{f}_{3}$ & 31.9372 & 9.24 & $32.6012^{\mathrm{b}}$ & 8.67 & 32.8924 & 8.42 & 33.4069 & 8.01 \\
$\mathrm{f}_{4}$ & 63.0397 & 9.48 & $65.0439^{\mathrm{b}}$ & 9.36 & 66.0436 & 9.30 & 68.0324 & 9.15 \\
\hline
\end{tabular}

${ }^{a}$ the first natural frequency is zero due to the rigid body rotation of whole system (without vibration)

${ }^{b}$ powertrain natural frequencies are used to validate the ATVA effectiveness.

The powertrain vibration mode shapes of the first gear, for example, are showed in figure 2.

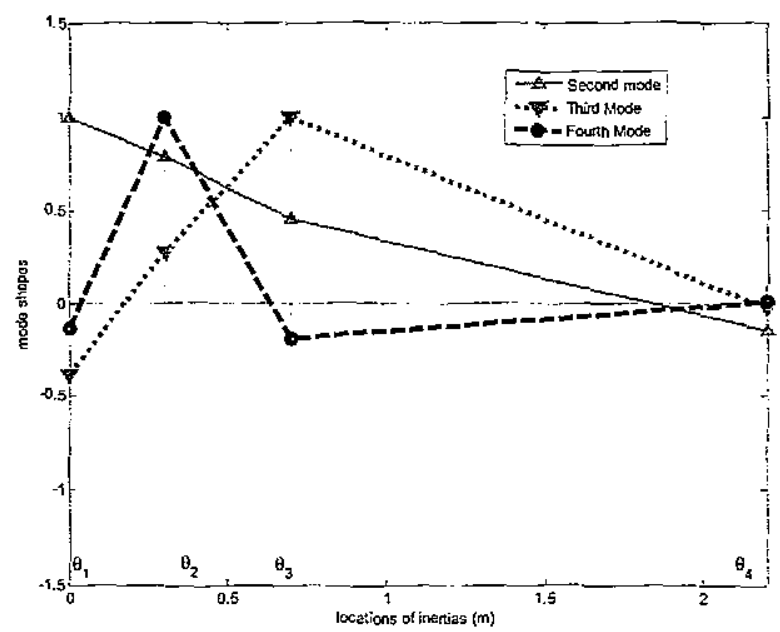

Figure 2. The second, third and fourth mode shapes of the first gear of gear box.

It can be seen the second mode is sensitive to either the first, second or third inertia. In other words, the second frequency powertrain can be shifted away if an ATVA is added to these three inertias. Meanwhile, the third and fourth modes seem to be only sensitive to the third and second inertia, respectively. If only a single ATVA is installed at a fixed position in the powertrain, it will not be able to deal with resonances happening to all the three vibration mode shapes.

\section{A PROPOSED DUAL ATVA}

From the powertrain mode shapes as shown in figure 2, the dual ATVA location is proposed as in figure 3 . Here, single ATVAs 1,2 are installed on the side of transmission box (third inertia- $\mathrm{J}_{2}$ ) and clutch (second inertia- $\mathrm{J}_{3}$ ), respectively.

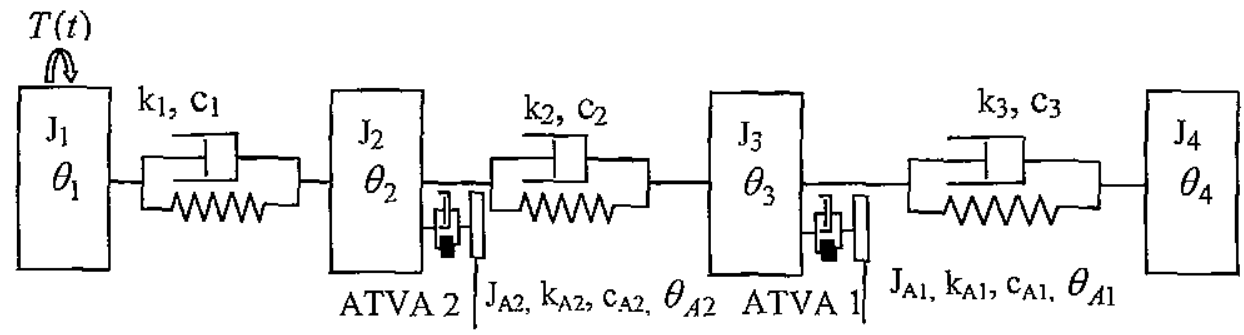

Figure 3. Powertrain with dual ATVA.

This combination of the two single ATVAs is the best because ATVA 1 can deal with the resonances, which occur to the second and the third powertrain vibration modes and ATVA 2 can work effectively for dealing with the resonances happening to the second and the fourth modes. Thus, all three powertrain vibration frequency can be deal with if any resonance happens to one of these three frequencies. 
After the dual ATVA is attached to the powertrain as in figure 3, the equation of motion keeps the same form as equation (1) but $\boldsymbol{\theta}=\left[\theta_{1} \theta_{2} \theta_{3} \theta_{4} \theta_{A 1} \theta_{A 2}\right]^{T} ; \mathbf{J}=\operatorname{diagonal}\left(\mathrm{J}_{1}, \mathrm{~J}_{2}, \mathrm{~J}_{3}, \mathrm{~J}_{4}, \mathrm{~J}_{\mathrm{Al}}, \mathrm{J}_{\mathrm{A} 2}\right)$ and stiffness matrix has following form:

$$
\mathbf{K}=\left[\begin{array}{cccccc}
k_{1} & -k_{1} & 0 & 0 & 0 & 0 \\
-k_{1} & k_{1}+k_{2}+k_{A 2} & -k_{2} & 0 & 0 & -k_{A 2} \\
0 & -k_{2} & k_{2}+k_{3}+k_{A 1} & -k_{3} & -k_{A 1} & 0 \\
0 & 0 & -k_{3} & k_{3} & 0 & 0 \\
0 & 0 & -k_{A 1} & 0 & k_{A 1} & 0 \\
0 & -k_{A 2} & 0 & 0 & 0 & k_{A 2}
\end{array}\right]
$$

The damping matrix $\mathbf{C}$ has the same form as the stiffness matrix $\mathbf{K}$.

\subsection{A soft magnetorheological elastomer and a proposed model of shear modulus}

Abramchuk et al..$^{15}$ presented a soft MRE material under a magnetic flux density $\mathrm{B}_{\max }=0.4 \mathrm{~T}$. This MRE sample based on a silicone polymer matrix and magnetic particles with volume concentration is $27.6 \%$. In addition, the magnetic particles are ferrous powders whose sizes range from 2-3 $\mu \mathrm{m}$ and the polymer matrix is a liquid silicone rubber of two mixing components. The first component is silicone oligomer with vinyl groups and the second one is silicone oligomer with hydride groups with the presence of platinum as a catalyst. As a result, the soft MRE has a large MR effect (the increase in shear modulus is 100 times)

According to the authors, at $\mathrm{B}=0$ and at $\mathrm{B}=\mathrm{B}_{\mathrm{S}}=0.3-0.4$ Tesla (saturated point), shear modulus $\mathrm{G}$ reaches minimum and maximum values, $\mathrm{G}_{0}$ and $\mathrm{G}_{\max }(3.5 \mathrm{kPa}$ and $350 \mathrm{kPa})$, respectively. Although the shear modulus of the soft MRE was numerically reported, it is convenient for the ATVA design if the shear modulus $G$ can be modelled as an explicit function of magnetic flux density B.

Stepanov et al. ${ }^{16}$ tested several MRE samples which has components similar to the soft MRE in this study and reported that elastic modulus curve relative to magnetic flux density B has S-shaped. In this study the shear modulus of the soft MRE can be modelled as a cubic polynomial of magnetic flux density $B$ as below:

$$
G=G(B)= \begin{cases}G_{0} & B \leq 0 \\ G_{0}+\sum_{0}^{3} c_{i} B^{i} & 0<B<B_{S} \\ G_{\max } & B \geq B_{S}\end{cases}
$$

Where $c_{i}, \mathrm{j}=0 . .3$, are coefficients. These coefficients can be determined from four conditions such that $G(0)=G_{0}, G\left(B_{S}\right)=G_{\max }, G^{\prime}(0)=0, G^{\prime}\left(B_{S}\right)=0$. With few calculations, it is straightforward to obtain the coefficients $c_{i}$ and the shear modulus $\mathrm{G}$ can be represented in the flowing form:

$$
G= \begin{cases}G_{0} & B \leq 0 \\ G_{0}+\left(G_{\max }-G_{0}\right) \frac{B^{2}}{B_{S}^{2}}\left(3-2 \frac{B}{B_{S}}\right) & 0<B<B_{S} \\ G_{\max } & B \geq B_{S}\end{cases}
$$

To validate this proposed model as equation (5), it is compared to experiment data as shown in figure 4 . In which, the data is expressed in term of logarithm of the relative change $(\mathrm{G} / \mathrm{G} 0)$ relative to the magnetic field intensity $\mathrm{H}$. Abramchuk et al. ${ }^{15}$ showed that that before the saturated point $\mathrm{B}_{\mathrm{S}}=0.35 \mathrm{~T}$ the relationship between magnetic flux density $\mathrm{B}$ and magnetic intensity $\mathrm{H}$ is linear, $B=\mu H \mathrm{H}$ where $\mu$ is the permeability.

It can be seen that the proposed model and experiment data are in agreement. With the effective model, the dual ATVA parameters such as stiffness and damping coefficients can be treated as explicit functions of magnetic field density $B$. 
Thus, the ATVA frequency can be tuned properly so that the proposed model is effective to design the dual ATVA.

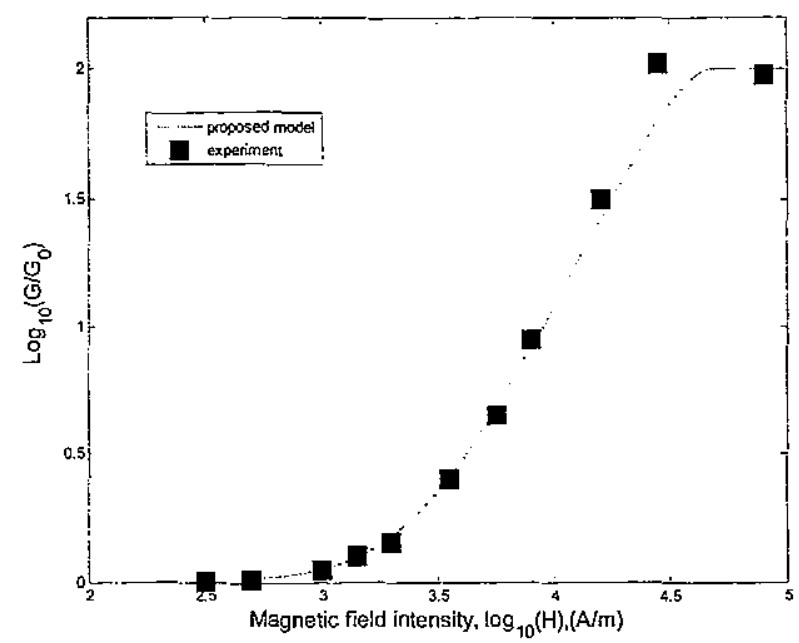

Figure 4. MRE shear modulus proposed model compared to experiment data by Abramchuk et $\mathrm{al}^{15}$.

\subsection{A proposed design of dual ATVA}

There are two similar single ATVAs in the dual ATVA. A proposed design of a single ATVA is shown in figure 5, in which the inner cylinder is fixed on the rotating shaft and the MRE material operating as a torsional spring is put into the gap between the inner and outer cylinder. There are lugs on the inner cylinder and the outer cylinder. These lugs cause elastic forces so that these cylinders can vibrate to each other. In addition, there are three magnetic circuits supplied by a DC current. Each of them consists of an electromagnetic coil and a steel core.
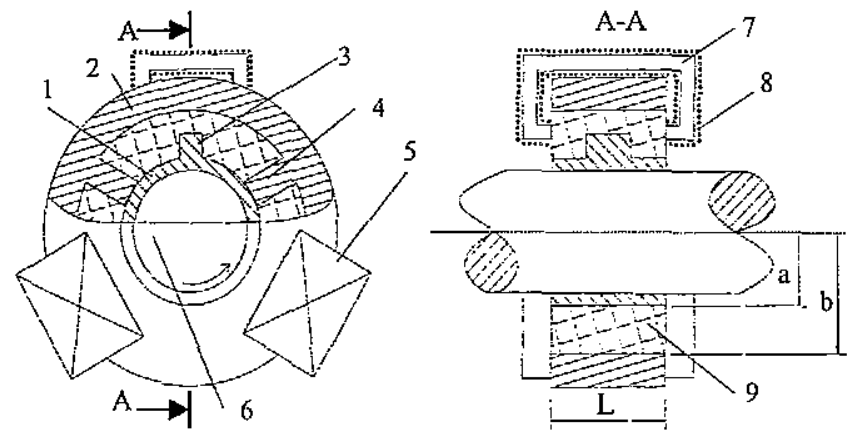

Figure 5. ATVA proposed design, 1,2: inner and outer cylinder; 3, 4: lugs in inner and outer cylinder; 5: magnetic circuit; 6: shaft; 7: steel core; 8: coil; 9: MRE.

According to Hoang et al. ${ }^{17}$, ATVA stiffness coefficient and inertia moment can be calculated by:

$$
\begin{aligned}
& k_{A}=\frac{4 \pi L a^{2} b^{2} G}{b^{2}-a^{2}} \\
& J_{A}=m\left(b^{2}+\frac{3 m_{\text {Bire }}}{m} d^{2}\right)=m R_{0}^{2}
\end{aligned}
$$

Where $\mathrm{m}, \mathrm{m}_{\text {Wire }}$ are masses of the outer ring and a wire coil, respectively; $\mathrm{d}$ is the distance from coil mass centre to the rotating shaft centre; $R_{0}$ is the ATVA equivalent gyration radius. For example, if $\mathrm{m}=2 \mathrm{~kg}, \mathrm{~b}=0.1 \mathrm{~m}, \mathrm{~m}_{\mathrm{Wirc}} / \mathrm{m}=0.25, \mathrm{~d}=0.2 \mathrm{~m}$ are given, $\mathrm{R}_{0}=0.2 \mathrm{~m}, \mathrm{~J}_{\mathrm{A}}=0.08 \mathrm{kgm} 2$ and inertia ratio $\mu_{A}=\mathrm{J}_{\mathrm{A}} / \mathrm{J}_{3}=0.2$ are calculated. For convenience $\mu_{A}$ can be varied to investigate the ATVA effectiveness. ATVA natural and damped frequencies are expressed as:

$$
\begin{aligned}
& f_{A}=\frac{1}{2 \pi} \sqrt{\frac{k_{A}}{J_{A}}} \\
& f_{d}=f_{A} \sqrt{1-\varsigma_{A}^{2}}
\end{aligned}
$$


$\varsigma_{A}$ is MRE damping ratio, and damping coefficient $\mathrm{c}_{\mathrm{A}}$ can be calculated as:

$$
c_{A}=2 \omega_{A} J_{A} \zeta_{A}=4 \pi f_{A} J_{A} \zeta_{A}
$$

Due to the damping of the soft MRE has not been reported yet, a damping model proposed by Zhou' will be used. According this author, the damping ratio is a slightly decreasing line (about $10 \%$ ). In this study, this damping model can be represented as below:

$$
\varsigma_{A}=\varsigma_{A}(B)=\varsigma_{0}-\frac{\varsigma_{0}-\zeta_{(}\left(B_{\max }\right)}{B_{\max }} B=\varsigma_{0}\left(1-\frac{B}{10 B_{\max }}\right)
$$

Here $\zeta\left(B_{\max }\right)=0.9 \varsigma_{0}$ was set and four zero-field damping ratios $\varsigma_{0}=0.05,0.10,0.25$ and 0.35 were set to examine the dual ATVA effectiveness. The ATVA main parameters and MRE properties is shown in Table 2.

Table 2. ATVA and the soft MRE material parameters

\begin{tabular}{cc}
\hline ATVA & MRE \\
\hline $\mathrm{a}=0.095 \mathrm{~m}$ & $\mathrm{G}_{0}=3.50 \mathrm{kPa}$ \\
$\mathrm{b}=0.1 \mathrm{~m}$ & $\mathrm{G}_{\max }=350 \mathrm{kPa}$ \\
$\mathrm{L}=0.045 \mathrm{~m}$ & $\mathrm{~B}_{\max }=0.5 \mathrm{~T}, \mathrm{~B}_{\mathrm{S}}=0.35 \mathrm{~T}$ \\
$\mu_{A}=0.2$ & $\varsigma_{0}=0.05,0.10,0.25$ and 0.35 \\
\hline
\end{tabular}

ATVA natural frequency $f_{n}$ and damped frequency $f_{d}$ are shown in figure 6 .

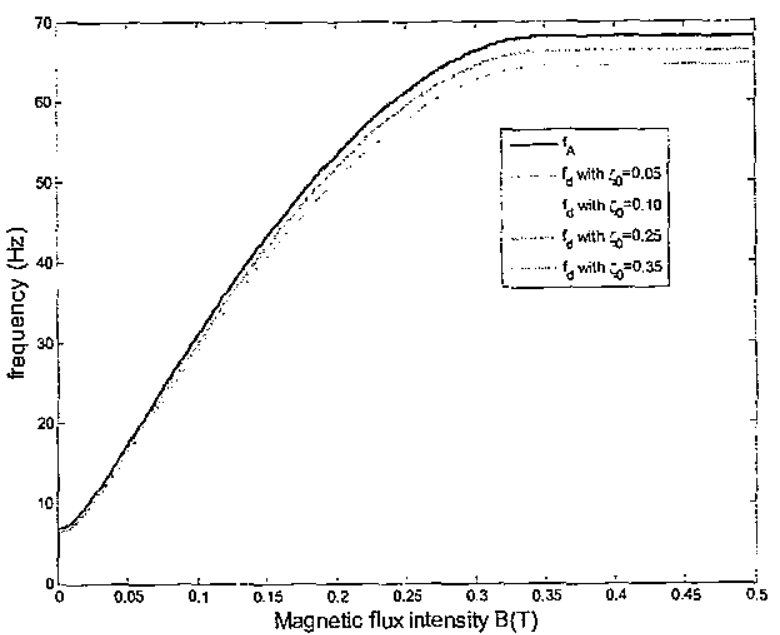

Figure 6. ATVA natural and damped frequencies with four zero-field damping ratios and $\mu_{A}=0.2$

It can be seen that ATVA frequency range covers all powertrain natural frequencies as shown in Table 1.

\section{DUAL ATVA FOR SUPRESSION OF POWERTRAIN VIBRATION}

According to Citron and $\mathrm{O}^{\prime}$ higgins ${ }^{8}$, the dynamic engine toque can be expressed in term of Fourier series as below

$$
T(t)=T_{m}+\sum_{n=1}^{N} T_{n} \sin \left(n \Omega t+\varphi_{n}\right)
$$

In which $\mathrm{N}$ is the number of harmonics. $\mathrm{T}_{\mathrm{n}}$ and $\varphi_{n}(\mathrm{n}=1 . . \mathrm{N})$ are amplitude and phase angle of $\mathrm{n}^{\text {th }}$ harmonic. $\Omega$ is the fundamental frequency and it depends on the number of cylinders of the engine and the engine speed. In this study, it is supposed that $\Omega$ is the same as that of engine speed. That means there are two cylinders in this engine. Here only vibration problem is considered and the mean torque $T_{m}$ is neglected.

In current work, it is assumed that the resonance can be happened in two cases: one resonance and two resonances at the same time. Accordingly, the application of the dual ATVA for each case will be investigated in next sections. 


\subsection{Application of dual ATVA for single resonance}

In this case, only the first harmonic is considered. From equation (12), the excitation fluctuation torque can be re-written as below:

$$
T=T_{1} \sin \left(\Omega t+\varphi_{1}\right)
$$

If the idle speed of engine is $660 \mathrm{rpm}$, this gives $\Omega=2 \pi \times 11(\mathrm{rad} / \mathrm{s})$, and it is noted that at engine idle speed, the first gear of gearbox is operated. As a result, the resonance may occur to the second frequency $\mathrm{f}_{2}=11.0494 \mathrm{~Hz}$ as noted in Table 1. If the frequencies of both single ones of the dual ATVA $f_{d}=11 \mathrm{~Hz}$ is tuned, let zero-field damping ratio $\varsigma_{0}=0.1$, inertia ratio $\mu_{A}=1 / 5$. By solving equation (9), the magnetic flux density $\mathrm{B}=0.0293(\mathrm{~T})$ is obtained. After that, from equations (6) and (10) ATVA stiffness and damping coefficients, $\mathrm{k}_{\mathrm{A}}$ and $\mathrm{c}_{\mathrm{A}}$, are computed. Then, the stiffness and damping matrix can be re-calculated by equation (3).

Let $T_{1}=5 \mathrm{Nm}, \varphi_{1}=0$. By solving the equation of motion of powertrain after adding the dual ATVA, the powertrain ribration frequency responses are shown in figure 7.
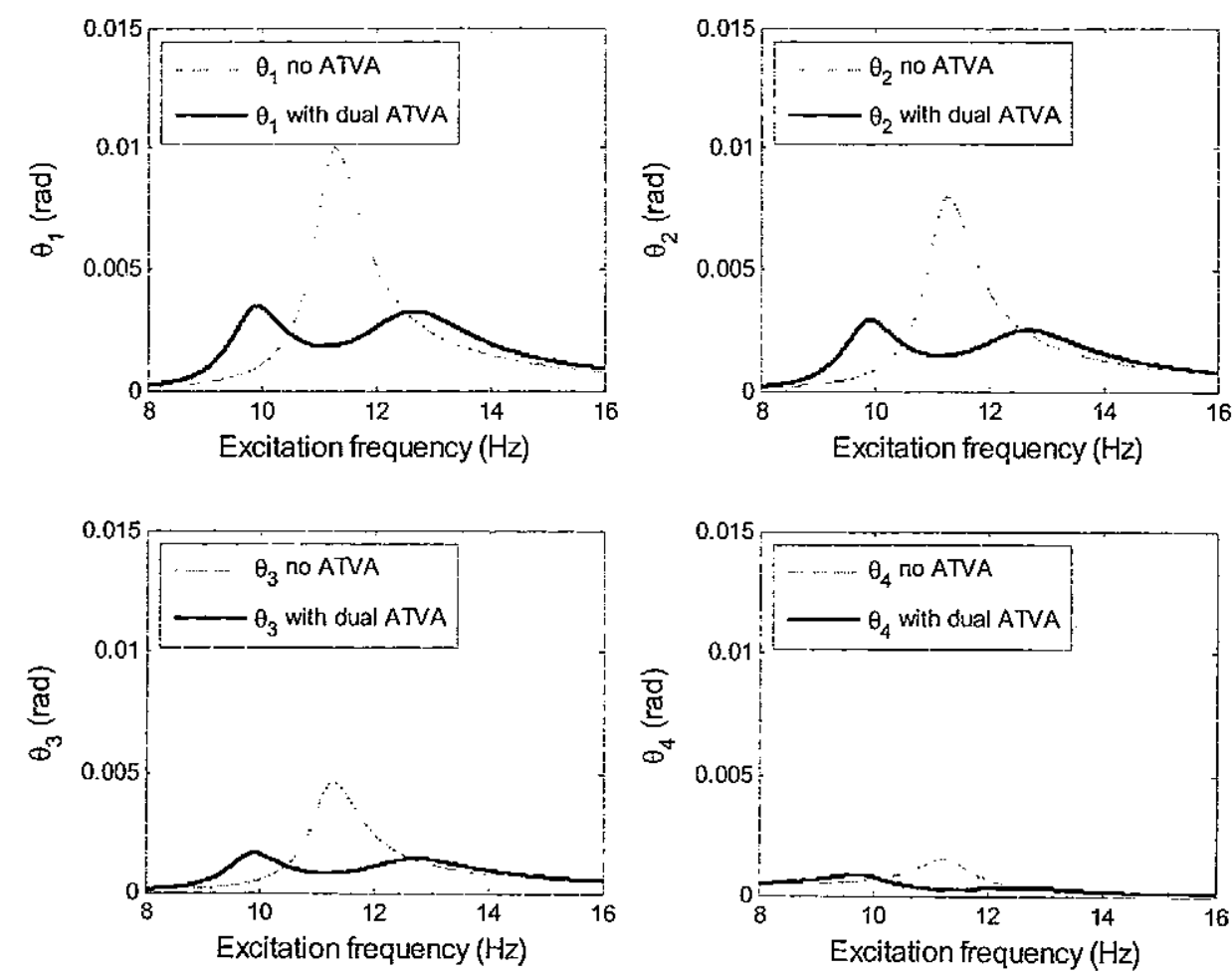

Figure 7. Powertrain vibration before and after adding dual ATVA.

Obviously, the vibration of the four inertias, $\theta_{1}, \theta_{2}, \theta_{3}$ and $\theta_{4}$ are reduced significantly after adding ATVA.

It can be seen that powertrain vibration frequency responses, which include four responses $\theta_{1}, \theta_{2}, \theta_{3}$ and $\theta_{4}$, are reduced significantly at and around the resonant frequency $\mathrm{f}_{2}=11 \mathrm{~Hz}$. For each of them, the resonant peak has been shifted to be two new ones as in figure 7. In other words, the dual ATVA has worked effectively because in this study the dual ATVA is considered to work effectively if the powertrain natural frequencies could be shifted away from the resonant peaks so that powertrain steady responses is reduced significantly. In addition, the responses at two invariant peaks, which are introduced after adding the dual ATVA as shown in figure 7, are small as well.

It is noted that the dual ATVA parameters such as inertia ratio, stiffness and damping coefficients can be varied to choose optimal values. With the optimal values, the response at resonant peak is small. Also, responses at the two invariant peaks are the same and small as well.

The effect of the dual ATVA inertia, damping and stiffness to its effectiveness will be discussed in following sections. 
To show how the dual ATVA damped frequency $f_{d}$ (ATVA stiffness as well) affects to its effectiveness, its several values such as $f_{d}=10.5,10.7,11$ and $11.5 \mathrm{~Hz}$ are varied to compare. With these values, the frequency vibration responses of the second inertia, $\theta_{2}$, are compared in figure 8 . It is noted that the ATVA frequency value $f_{d}$ is considered as optimal value if at the two invariant peaks, as in figure 8 , the frequency responses reach maximum values and these values are the same. It can be seen that the optimal frequency value of $\mathrm{f}_{\mathrm{d}}$ is between 10.7 and $11 \mathrm{~Hz}$ in this case.

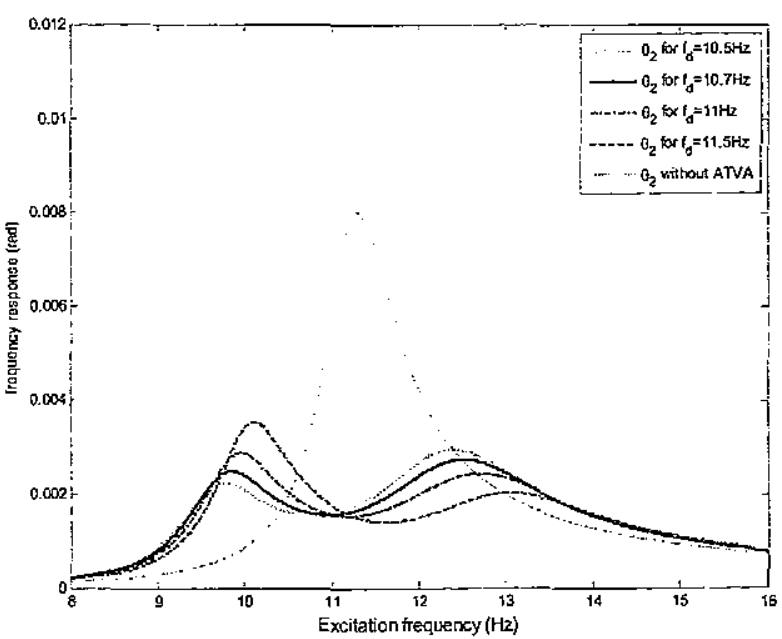

Figure. 8 Vibration of second inertia $\theta_{2}$ with several dual ATVA frequencies.

It is similar to show how the inertial moment $\mathrm{J}_{\mathrm{A}}$ and damping affect to the dual ATVA. Several values of inertial moment $\mathrm{J}_{\mathrm{A}}$ and zero-field damping ratios are chosen and the responses of second inertia $\theta_{2}$ are shown in figure 9 and 10 . Figure 9 shows responses of second inertia $\theta_{2}$ with several values of the inertia ratios $\mu_{A}=1 / 4,1 / 5,1 / 10,1 / 20$.

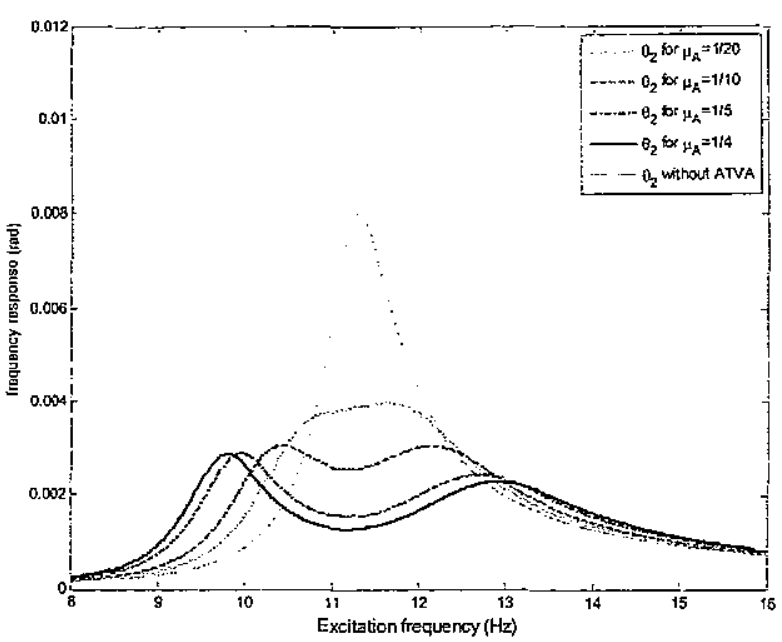

Figure. 9 Vibration of second inertia $\theta_{2}$ with several values of inertia ratio $\mu_{A}$.

It can be seen that the larger inertia ratio, the better vibration reduction effect the ATVA can be. For large inertia ratios $\mu_{A}=1 / 4, \mu_{A}=1 / 5$ the resonant peak is shifted far away by introducing two new invariant peaks. In contrast, for low inertia ratios $\mu_{A}=1 / 10$ or $1 / 20$ it is not because two new invariant frequency have not been shifted so that vibratior: response at the resonant frequency is reduced not much with these low inertia ratios as can be seen in figure 9 . In other words, if the inertia ratio is too small, the dual ATVA does not work. 
Figure 10 shows the effect of damping. Obviously, the less damping ratio is, the smaller response at the resonant frequency can be. However, a small damping ratio may result in high responses at the two invariant frequencies. For instant, for $\varsigma_{0}=0.05$ the response is the smallest at the resonant frequency but at two invariant peaks it is higher than those when $\varsigma_{0}=0.1$.

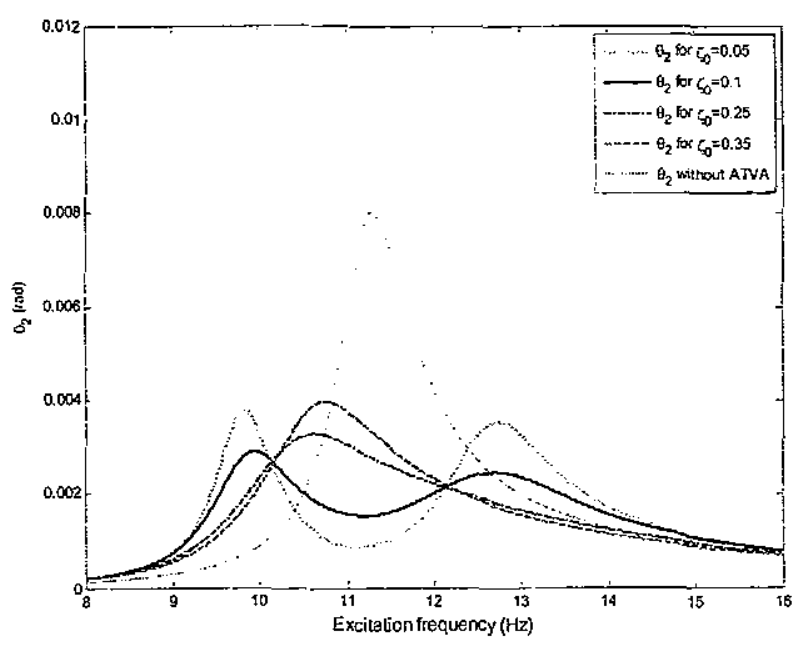

Figure. 10 Vibration of second inertia $\theta_{2}$ with several values of zero-field damping ratio $\varsigma_{0}=0.05,0.1,0.25$ and 0.35 .

If the excitation frequency $\Omega=2 \pi \times 32.5(\mathrm{rad} / \mathrm{s})$ (the engine speed is $1950 \mathrm{rpm}$ ) and the second gear of gear box is used. As a result, the resonance happens to the third frequency of second gear $\mathrm{f}_{3}=32.6012 \mathrm{~Hz}$ as noted in Table 1 . If each single ATVA frequency $\mathrm{f}_{\mathrm{d}}=30 \mathrm{~Hz}$ is tuned; let $\varsigma_{0}=0.25, \mu_{A}=1 / 4, \mathrm{~T}_{1}=50 \mathrm{Nm}, \varphi_{1}=0$, the frequency response of second inertia before and after adding ATVA is shown in figure 11.

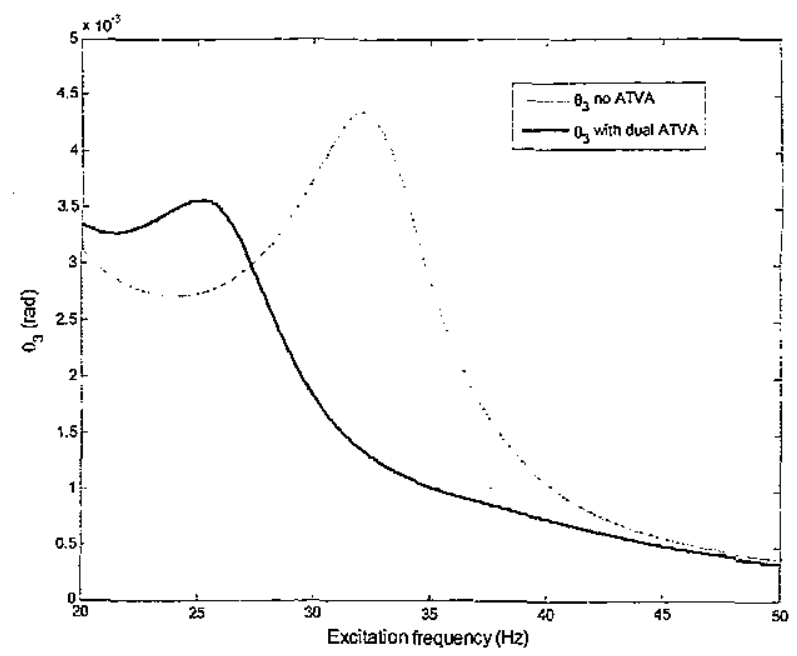

Figure 11. The second inertia response before and after adding dual ATVA for third frequency of second gear.

Similarly, the ATVA can deal with the resonance happening to the fourth frequency $\mathrm{f}_{4}=65.0439 \mathrm{~Hz}$ of second gear as zoted in Table 1 when $\Omega=2 \pi \times 65 \mathrm{rad}$ (at which engine speed is $3900 \mathrm{rpm}$ ).

Obviously, with the dual ATVA, the resonances occurring to all three modes of powertrain have been deal with. This can not be done if an ATVA is used singly. Especially, the dual ATVA is more effective for the case that there are two resonances, which happen at the same time. 


\subsection{Application of dual ATVA for two resonances}

If $\Omega=2 \pi \times 11(\mathrm{rad} / \mathrm{s})$ and the first and third harmonics of engine torque are dominated, the second harmonics can be neglected and the engine fluctuation torque can be re-written as:

$$
T=T_{1} \sin \left(\Omega t+\varphi_{1}\right)+T_{3} \sin \left(3 \Omega t+\varphi_{3}\right)
$$

With the powertrain frequency of the first gear as in Table 1, there are two resonances at the same time in this case $\mathrm{f}_{2}=11.0494 \mathrm{and} \mathrm{f}_{3}=31.9372 \mathrm{~Hz}$. To deal with, frequencies of ATVA 1 and ATVA 2 will be tuned as $\mathrm{f}_{\mathrm{d} 1}=32 \mathrm{~Hz}$ (to eliminate third mode) and $\mathrm{f}_{\mathrm{A} Z}=11 \mathrm{~Hz}$ (to eliminate second mode) as in figure 2. Let $\varphi_{1}=0, \varphi_{3}=\pi / 2 . \varsigma_{0}=0.25$ is chosen. $T_{1}=5 \mathrm{Nm}, T_{3}=35 \mathrm{Nm}$ are set. The response of powertrain is shown in figure 12 .
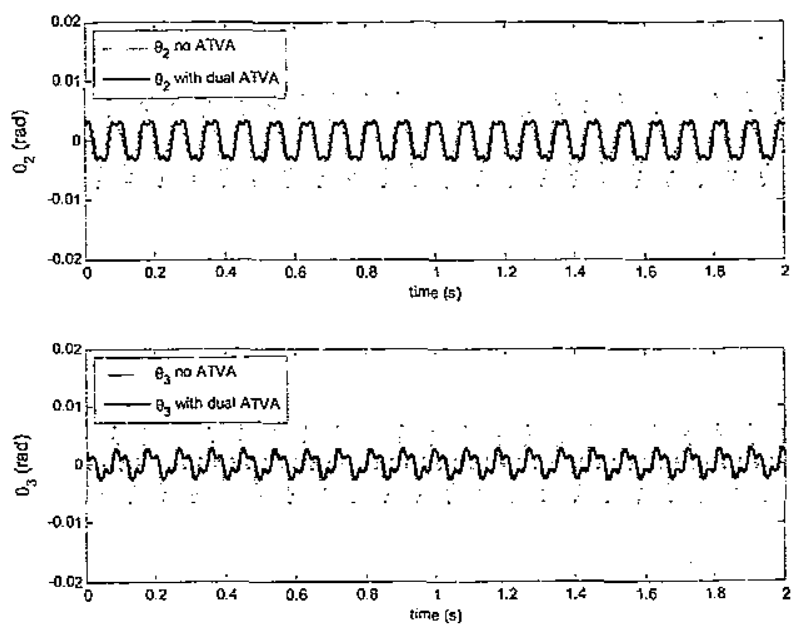

Figure 12. The powertrain torsional vibration before and after adding dual ATVA with $\Omega=2 \pi \times 11$ (rad). Obviously, the vibration has been reduced significantly after adding the dual ATVA.

To show the effect of the location of each ATVA, the time response $\theta_{3}$ is showed in figure 13 for three cases: before adding ATVA; after adding ATVA as shown in figure 3; and after adding but two ATVA swapped to each other.

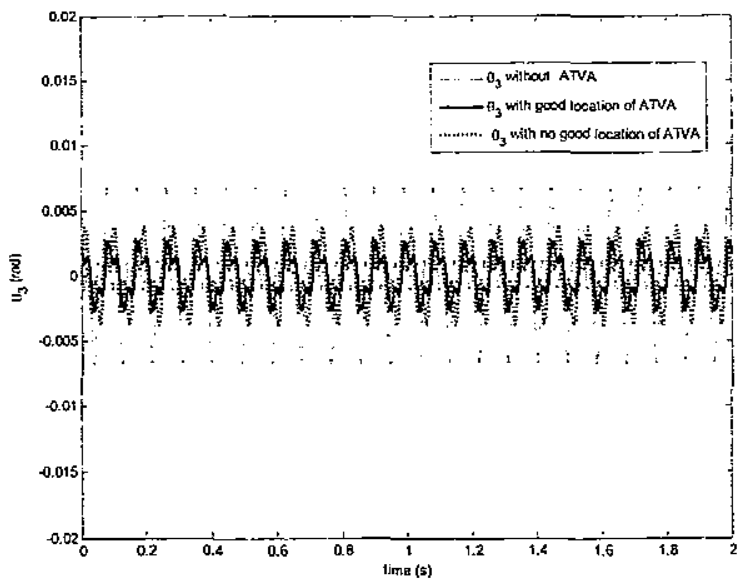

Figure 13. Effect of the dual ATVA location to its effectiveness

It can be seen that after the locations of single ATVA are swapped, the dual ATVA effectiveness is changed significantly. One more time, it can be seen that the location of dual ATVA is sensitive to it effectiveness. 
Similarly, if $\Omega=2 \pi \times 32.5(\mathrm{rad} / \mathrm{s})$ as in section 4.1(the engine speed is $1950 \mathrm{rpm})$. In this case it is assumed that the first and second harmonics are dominated, the third harmonics is neglected and the engine fluctuation torque is re-written as:

$$
T=T_{1} \sin \left(\Omega t+\varphi_{1}\right)+T_{2} \sin \left(2 \Omega t+\varphi_{2}\right)
$$

At this speed of engine the second gear of gear box is used. It can be seen from Table 1 with $\mathrm{f}_{3}=32.6012 \mathrm{~Hz}$ and $\mathrm{f}_{4}=65.0439 \mathrm{~Hz}$. One more time, there are two resonances happening at the same time. To deal with, frequencies of ATVA 1 and ATVA 2 will be tuned as $f_{\mathrm{d} 1}=32 \mathrm{~Hz}$ (to eliminate third mode) and $f_{A 2}=65 \mathrm{~Hz}$ (to eliminate fourth mode) as in figure 2.

Let phase angles $\varphi_{1}=0, \varphi_{2}=\pi / 2$, zero-field damping ratio $\varsigma_{0}=0.35$ is chosen. $T_{1}=5 \mathrm{Nm}, \mathrm{T}_{2}=35 \mathrm{Nm}$ are set. The response of powertrain is shown in figure 14 .
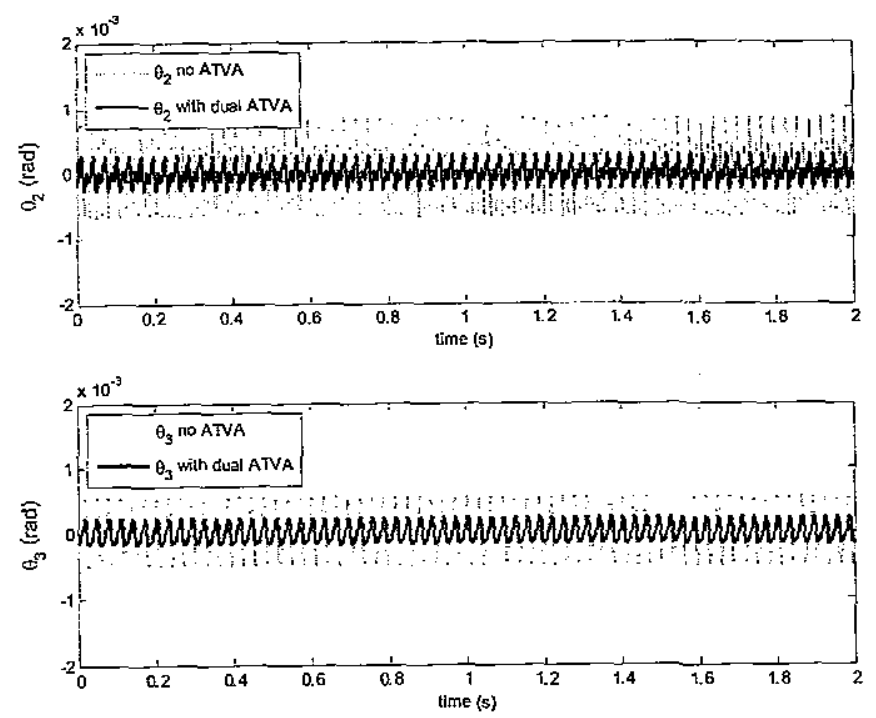

Figure 14. The powertrain torsional response before and after adding dual ATVA with $\Omega=2 \pi \times 32.5$ (rad).

Obviously, the dual ATVA work effectively because the vibration responses have been reduced significantly. It is noted that the resonances cannot be if an ATVA is used singly.

It can be seen that three resonant cases, which happened to all three vibration modes of powertrain has been deal with by tuning the dual ATVA frequency. This problem can not be deal with if an ATVA is used singly.

\section{CONCLUSIONS}

A dual dynamic absorber using a soft MRE is presented in this study for powertrain vibration reduction. With the dual MRE-based ATVA, the unwanted vibrations of powertrain when resonances happen to vibration modes of powertrain are eliminated. To facilitate the ATVA design phase, an effective formula of a soft MRE shear modulus is proposed. The model is experimentally validated and it is used effectively for tuning ATVA parameters according to the engine speed.

By using the dual ATVA, powertrain resonant frequencies are shifted away excitation frequencies so that its vibration response is significantly suppressed. In addition, the effect of the dual ATVA parameters such as inertia moment, stiffness and damping coefficients to its effectiveness were examined. As a result, optimal parameters of dual ATVA can be obtained. Furthenmore, basing on powertrain vibration mode shapes, the best location of dual ATVA is proposed. Thus, resonances happening to all powertrain vibration modes can be deal with while these resonances cannot be done if an ATVA is used singly. The dual ATVA will be a useful device for powertrain vibration suppression.

The effectiveness of the dual ATVA for powertrain vibration during the transient stage, when excitation frequencies of fluctuation torque are not constant but vary with the time, over a frequency range and the application of the MRE proposed model of shear modulus will be our next work. 


\section{REFERENCES}

1. Zhou, G. Y., "Shear properties of a magnetorheological elastomer," Smart Material and Structure, 12, 139-46(2003).

2. Kallio, M., "The elastic and damping properties of magnetorheological elastomers," VTT Publishers, Finland, 565 (2005).

3. Ginder, J. M., Schlotter, W. F. and Nichols, M. E., "Magnetorheological elastomers in tunable vibration absorbers," Proc. SPIE 433I, 103-10 (2001).

4. Deng, H. X., Gong, X.L and Wang, L. H., "Development of an adaptive tuned vibration absorber with magnetorheological elastomer, "J. Smart Mate Structure, 15, 111-16 (2006).

5. Lerner, A.A.and Cunefare, K. A., "Performance of MRE-based Vibration Absorbers," J. Intelligent Material Systems and Structures, 19, 551-563 (2008).

6. Zhang, N., Crowther, A., Liu, D., K. and Jeyakumaxan, J., "A finite element method for the dynamic analysis of automatic transmission gear shifting with a four-degree-of-freedom planetary gearset element, "Proc. of the Instn of Mech Engrs Part D: Journal of Automobile Engineering, 217, 461-73 (2003).

7. Couderc, P., Callenaere, J., Der Hagopian, J., Ferraris G., Kassai, A., Borjesson, Y., Verdillon, L. and Gaimard, S., "Vehicle driveline dynamic behaviour experimentation and simulation, "Joumal of Sound and Vibration, 218, 13357(1998).

8. Citron, S.J. and O'higgins J.E., "Cylinder-by-cylinder engine pressure and pressure torque waveform determination utilizing crankshaft speed fluctuations, "US Patent number: 4,843,870 (1989).

9. Yamashita, S., Seto, K., and Hara, F., "Vibration control in piping system by dual dynamic absorber (Realization of piping systems with unresonant characteristics)," JSME international journal, 33 (4), 488-494 (1990).

10. Yan, T. H. and Lin, R. M., "Dual-Mass Dynamic Absorber for the Head Actuator Assembly in Hard Disk Drives, " Mechanics based design of structures and machines 32(2), 119-132 (2004).

11. Burdisso, R.A. and Heilmann J. D., "A new dual-reaction mass dynamic vibration absorber actuator for active vibration, ", Joumal of sound and vibration, 214 (5), 817-831(1998).

12. Iwanami, K., Seto, K., "An optimum design method for the dual dynamic damper and its effectiveness, "Bulletin of JSME, 27(231), 1965-1973 (1984).

13. Al-Bedoor, B. O., Moustafa, K. A., and Al-Hussain, K. M., "Dual dynamic absorber for the torsional vibrations of synchronous motor-driven compressors, "Journal of Sound and Vibration, 220(4), 729-748 (1999).

14. Zhang, N., Hoang, N. and Du, H., "A novel dynamic absorber using enhanced magnetorheological elastomers for powertrain vibration control," Proc. Advanced Materials Research, July 28-31, Hong Kong, China, $117-120$ (2008).

15. Abramchuk, S. S., Grishin, D. A., Kramarenko, E. Y., Stepanov, G. V. and Khokhlov, A. R., "Effect of a homogeneous magnetic field on the mechanical behavior of soft magnetic elastomers under compression," Journal of Polymer Science Part A, 48(2), 138-145 (2006).

16. Stepanov, G. V., Abramchuk, S. S., Grishin, D. A., Nikitin, L. V., Kramarenko, E. Y. and Khokhlov, A. R., "Effect of a homogeneous magnetic field on the viscoelastic behaviour of magnetic elastomers, "Polymer 48, 488-95 (2007).

17. Hoang, N., Zhang, N. and Du, H., "A dynamic absorber with a soft magnetorheological elastomer for powertrain vibration suppression," Smart Material and Structure, 18 (7), 074009 (2009). 
The papers included in this volume were part of the technical conference cited on the cover and title page. Papers were selected and subject to review by the editors and conference program committee. Some conference presentations may not be available for publication. The papers published in these proceedings reflect the work and thoughts of the authors and are published herein as submitted. The publisher is not responsible for the validity of the information or for any outcomes resulting from reliance thereon.

Please use the following format to cite material from this book:

Author(s), "Title of Paper," in Active and Passive Smart Structures and Integrated Systems 2010, edited by Mehrdad N. Ghasemi-Nejhad, Proceedings of SPIE Vol. 7643 (SPIE, Bellingham, WA, 2010) Article CID Number.

ISSN 0277-786X

ISBN 9780819480583

Published by

SPIE

P.O. Box 10, Bellingham, Washington 98227-0010 USA

Telephone +1 3606763290 (Pacific Time) · Fax +1 3606471445

SPIE.org

Copyright (C) 2010, Society of Photo-Optical Instrumentation Engineers

Copying of material in this book for internal or personal use, or for the internal or personal use of specific clients, beyond the fair use provisions granted by the U.S. Copyright Law is authorized by SPIE subject to payment of copying fees. The Transactional Reporting Service base fee for this volume is $\$ 18.00$ per article (or portion thereof), which should be paid directly to the Copyright Clearance Center (CCC), 222 Rosewood Drive, Danvers, MA 01923. Payment may also be made electronically through CCC Online at copyright.com. Other copying for republication, resale, advertising or promotion, or any form of systematic or multiple reproduction of any material in this book is prohibited except with permission in writing from the publisher. The CCC fee code is 0277-786X/10/\$18.00.

Printed in the United States of America.

Publication of record for individual papers is online in the SPIE Digital Library.

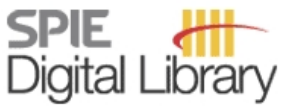

SPIEDigitalLibrary.org

Paper Numbering: Proceedings of SPIE follow an e-First publication model, with papers published first online and then in print and on CD-ROM. Papers are published as they are submitted and meet publication criteria. A unique, consistent, permanent citation identifier (CID) number is assigned to each article at the time of the first publication. Utilization of CIDs allows articles to be fully citable as soon they are published online, and connects the same identifier to all online, print, and electronic versions of the publication. SPIE uses a six-digit CID article numbering system in which:

- The first four digits correspond to the SPIE volume number.

- The last two digits indicate publication order within the volume using a Base 36 numbering system employing both numerals and letters. These two-number sets start with 00, 01, 02, 03, 04, $05,06,07,08,09,0 A, 0 B \ldots 0 Z$, followed by 10-1Z, 20-2Z, etc.

The CID number appears on each page of the manuscript. The complete citation is used on the first page, and an abbreviated version on subsequent pages. Numbers in the index correspond to the last two digits of the six-digit CID number. 